\title{
An overview of complications of MSICS
}

\author{
N. Lakshmi Chowdary 1,", B. Pradhan ${ }^{2}$ \\ ${ }^{1}$ Professor and Head, ${ }^{2}$ Post Graduate Dept. of Ophthalmology, NRI Medical College \& General Hospital, Guntur, Andhra \\ Pradesh, India
}

*Corresponding Author: N. Lakshmi Chowdary

Email: laxmieye@gmail.com

\begin{abstract}
Introduction: Taking into consideration the wide spectrum of complications that follow MSICS and their influence on visual outcome, a sincere effort has been made in this study to critically analyze the incidence and the nature of various intraoperative, early and late post-operative complications among the total number of cataract extraction carried out.

Materials and Methods: A Prospective observational study of 500 cases that had undergone MSICS after a thorough preoperative ocular evaluation including detailed history and clinical examination and these cases were studied for a period of 2 years and all the intraoperative, early and late post-operative complications were noted.

Results: The commonest intraoperative complications were premature entry with iris prolapse (5\%) followed by zonular dialysis (3\%), commonest early post operative complications were SK (20\%) and corneal edema (17\%) and the commonest late post operative complications were $\mathrm{PCO}(18 \%)$ followed by astigmatism in $9 \%$ of the cases.

Conclusion: SICS gives best corrected postoperative visual acuity of $6 / 6$ or $6 / 9$ in a greater proportion of patients and it has all the inherent advantages of the sutureless cataract surgery in terms of universal applicability, greater wound stability, lesser complications and early visual rehabilitation.
\end{abstract}

Keywords: Cataract surgery, Complications of MSICS, MSICS, Phacoemulsification.

\section{Introduction}

The commonest cause of blindness in the world is due to cataract and its incidence is about $55 \%$ of all causes of blindness in India. ${ }^{1}$ An estimated 4 million people become blind because of cataract every year, ${ }^{2}$ which is added to a backlog of 10 million operable cataracts in India, whereas only 5 million cataract surgeries are performed annually in the country. ${ }^{3}$ Thus, a technique of cataract surgery that is not only safe and effective but also economical and easy for the majority of ophthalmologists to master is the need of the hour. The quality of vision and the patients comfort and acceptance of correction of the surgically induced hypermetropia by way of aphakic spectacles or contact lenses is not optimum. Ridleys work has paved the research and development of intraocular lens implantation. The classical extra capsular technique employs a large incision into the eye that requires several sutures and the visual rehabilitation is delayed to about 6 weeks. Advances in cataract surgery have been possible due to better visualization with the help of operating microscopes. These have been three fold, lens removal technique, incision and IOL design, each being interdependent. ${ }^{4,5}$ Though phacoemulsification provides rapid visual rehabilitation, its application to the community need is limited by cost, long learning curve, dependence on machine and trained personnel. In the view of community need, Manual Small Incision Cataract Surgery (MSICS) was developed which offers several advantages including better safety and earlier visual rehabilitation. MSICS to be more effective, ${ }^{6}$ and economical ${ }^{7}$ than ECCE and almost as effective as ${ }^{8}$ and more economical than phacoemulsification. We feel that a study and careful analysis of the results is essential for our population, in view of prevailing illiteracy, ignorance, low socioeconomic status. With this view we have taken a study of the complications in MSICS.

\section{Materials and Methods}

This prospective study was taken up after taking the approval of institutional ethics committee. 500 eyes of 500 patients who met the below criteria were included in the study.

\section{Inclusion Criteria}

1. Patient admitted in ophthalmology ward undergoing Cataract Surgery [SICS]

2. Patients who are diagnosed with Senile Cataract

\section{Exclusion Criteria}

1. Paediatric cataracts

2. Traumatic cataracts

3. Complicated cataracts

Pre-Operative Examination and Investigations: Visual acuity of $6 / 60$ was found in $70 \%$ cases, most of it were the cases of IMSC and nuclear cataract. All patients fulfilling the inclusion criteria were subjected to thorough ocular examination which includes detailed history and clinical examination.

1. Complete ocular examination was done which included visual acuity, unaided and best corrected, complete and detailed slit lamp examination, fundus examination, B scan when needed, IOP measurement, NLD patency, Keratometry, A-Scan biometry, xylocaine sensitivity test and IOL power calculation.

2. Investigations were done which included: Blood pressure, blood sugar level $\&$ urine examination. 
All patients were subjected to detailed general and physical examination and preoperative fitness was taken from physician whenever needed.

3. Preop Preparation: The patients were explained about the surgery advantages and disadvantages of posterior chamber intra ocular lens implantation (Health Counseling) and written consent was obtained from all cases. The day before surgery each patient was instructed to have scrub bath including face and hair and the following drugs were given

a. Topical antiboitic eye drops Q.I.D for 3 days before surgery.

b. Anxiolytic drugs like Tab. Diazepam $5 \mathrm{mg}$ at bed time. IOP lowering drugs like Tab. Diamox 250mg 1 tab at bed time.

On the day of surgery, morning the patients were given following drugs.

1. Tab. Ciprofloxacin $500 \mathrm{mg}$ (1 stat)

2. Tab. Diamox $250 \mathrm{mg}$ (1 stat)

3. Adequate mydriasis was obtained with $10 \%$ phenylephrine, 1\% Tropicamide eye drops and NSAID eye drops / every 15 minutes 4-5 times before surgery.

Surgical Technique: All the surgeries were performed by different surgeons and the incision was superior in all the cases. All the observations were noted. Postoperatively eyes were patched after giving subconjunctival injection of gentamycin and dexamethasone. All the study participants were observed for the occurrence of any intraoperative complications while undergoing Small Incision Cataract Surgery with their subsequent management

Post-operative Treatment: The first post-operative dressing was done on the day following surgery and eye is inspected for any post-operative complication under slit lamp biomicroscopy. Naked eye vision and vision with pin hole recorded. Fundus was examined with direct ophthalmoscopy. All Patients were put on routine regime of a. Steroid antibiotic drops / 1 drop / 6times /day, b. Cycloplegic drops (1\% Cyclopentolate) / 1drop
12 Times a day, c. Tab. Ciprofloxacin $500 \mathrm{mg}$ bd for 5 days, d. Tab. Combiflam 500mg Bid for 3 days e. Tab. Rantac $150 \mathrm{mg}$ bd for 5 days. Whenever there is postoperative corneal edema and striate keratopathy, the patients were given hourly topical steroids, $0.50 \%$ timolol maleate eye drops twice daily and acetazolamide $250 \mathrm{mg}$ bd for 2 days. Whenever there is post-operative Uveitis the patients were given subconjunctival dexamethasone injection, topical steroids, systemic steroids and NSAID eye drops and cycloplegic-mydriatic eye drops. Discharge: Patients without post-operative complications were discharged on 2 nd post-operative day. Patients with post-operative complications were discharged after treating the complications. On the day of discharge visual acuity with pin hole and naked eye vision recorded. Slit lamp biomicroscopy of anterior segment \& fundus examination with direct ophthalmoscopy was done. Post-operative Follow up: The patients were instructed to attend the hospital on OP days as follows:

First follow up visit: After 1 Week

Second follow up visit: After 3 Weeks

Third follow up visit: After 6 Weeks and after that every three months

In every visit the following tests were routinely done:

Visual acuity, slit lamp biomicroscopy, fundus examination \& retinoscopy was done 4 weeks after surgery. Patients with high astigmatism, tight suture was removed. Intra Ocular pressure recording done after 6 weeks and after 3 months in cases with corneal edema due to raised IOP. After 6 weeks retinoscopy was done for all cases and necessary correcting glasses were prescribed.

\section{Results}

The commonest type of cataract seen was immature senile cortical cataract seen in $44 \%$ of cases followed by nuclear cataract in $41 \%$ of cases. This is again in conformity with incidence of senile cataract, the percentage of which raises with age (Table 1 ).

Table 1: Types of cataract, age \& sex distribution

\begin{tabular}{|c|c|c|c|c|c|c|c|}
\hline \multirow[t]{2}{*}{ Age } & \multicolumn{2}{|c|}{ IMSC } & \multicolumn{2}{|c|}{ MSC } & \multicolumn{2}{|c|}{$\mathbf{N C}$} & \multirow[t]{2}{*}{ Total } \\
\hline & Males & Females & Males & Females & Males & Females & \\
\hline $45-54$ & 10 & 40 & 0 & 0 & 25 & 20 & 95 \\
\hline $55-64$ & 20 & 60 & 10 & 5 & 30 & 35 & 160 \\
\hline$>64$ & 55 & 35 & 40 & 20 & 40 & 55 & 245 \\
\hline Total & 85 & 135 & 50 & 25 & 95 & 110 & 500 \\
\hline
\end{tabular}

The preoperative VA was appreciation of Hand movements (HM) or less in $20 \%$ cases, most of it were mature cataracts. The visual acuity ranging from counting fingers to greater than $6 / 60$ in 50 patients before surgery.

Premature entry with iris prolapse was the most common complication seen in $5 \%$ of cases, followed by
Zonular dialysis in $3 \%$ of cases. PCR, DM tear, Button holing each of which was seen in $2 \%$ of cases. Superior and inferior dialysis each in $1 \%$ of cases (Table 2 ) 
Table 2: Incidence of intra operative complications

\begin{tabular}{|l|c|c|}
\hline Intra op complications & $\begin{array}{c}\text { No. of } \\
\text { cases }\end{array}$ & $\mathbf{\%}$ \\
\hline DM tear & 10 & 2 \\
\hline PCR & 10 & 2 \\
\hline Button hole & 10 & 2 \\
\hline Premature entry & 25 & 5 \\
\hline Irisprolapse & 25 & 5 \\
\hline Zonular dialysis & 15 & 3 \\
\hline Superior Iridodialsis & 5 & 1 \\
\hline Inferior iridodialysis & 5 & 1 \\
\hline
\end{tabular}

SK was the most common early post-operative complication seen in $20 \%$ of cases, corneal edema in $17 \%$ of cases, Iritis in 9\% of cases. Iris prolapse, retained lensmatter, hyphema, decentered IOL each of which in $2 \%$ of the cases (Table 3 ).

Table 3: Incidence of early post-operative complications

\begin{tabular}{|l|c|c|}
\hline $\begin{array}{l}\text { Early postop } \\
\text { complications }\end{array}$ & $\begin{array}{c}\text { No. of } \\
\text { persons }\end{array}$ & $\mathbf{\%}$ \\
\hline Striate ketopathy & 100 & 20 \\
\hline Corneal edema & 85 & 17 \\
\hline Iritis & 45 & 9 \\
\hline Iris prolapse & 10 & 2 \\
\hline Retained cortical matter & 10 & 2 \\
\hline Hyphema & 10 & 2 \\
\hline Decentred IOL & 10 & 2 \\
\hline
\end{tabular}

\section{Incidence of early Postop complications}

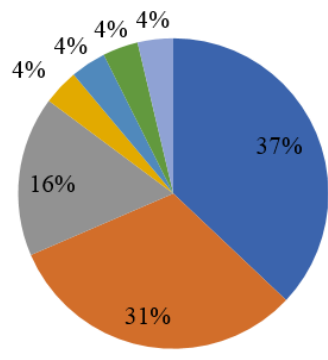

$$
\begin{aligned}
& \text { - Stirate ketopathy } \\
& \text { - Corneal edema } \\
& \text { - Iritis } \\
& \text { Irisprolapse } \\
& \text { - Retained cortical matter } \\
& \text { - Hyphema }
\end{aligned}
$$

\section{Fig. 1}

PCO was the most common delayed post-operative complication seen in $18 \%$ of cases, astigmatism in $9 \%$ of cases, pupillary capture in $2 \%$ of the cases and corneal decompensation in $1 \%$ of the cases (Table 4).

Table 4: Incidence of delayed post-operative complications

\begin{tabular}{|l|c|c|}
\hline $\begin{array}{c}\text { Delayed postop } \\
\text { complications }\end{array}$ & $\begin{array}{c}\text { No. of } \\
\text { persons }\end{array}$ & $\mathbf{\%}$ \\
\hline Posterior capsular opacity & 90 & 18 \\
\hline Astigmatism & 45 & 9 \\
\hline Pupillary capture & 10 & 2 \\
\hline corneal decompensation & 5 & 1 \\
\hline
\end{tabular}

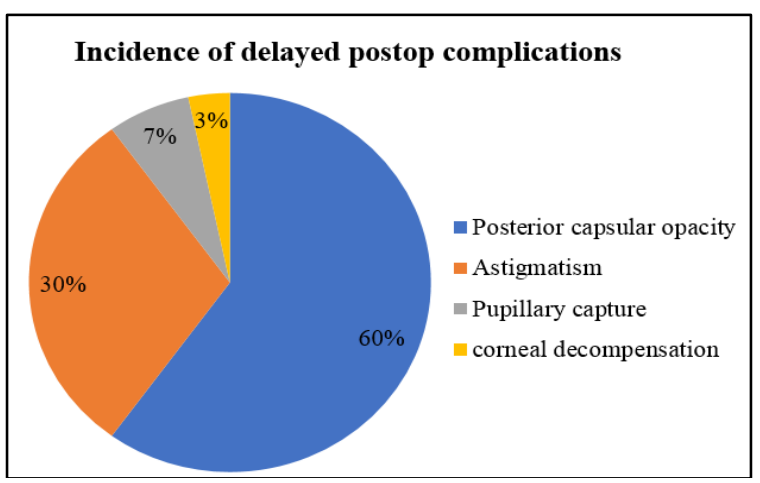

Fig. 2

Post-operative visual outcome was borderline in $23 \%$ cases and good in $77 \%$ cases (Table 5).

Table 5: Post-operative visual outcome

\begin{tabular}{|l|c|c|}
\hline Postop visual outcome & No. of cases & \% \\
\hline Boarder line & 115 & 23 \\
\hline Good & 385 & 77 \\
\hline Poor & 0 & 0 \\
\hline Total & 500 & 100 \\
\hline
\end{tabular}

\section{Discussion}

Incidence of intraoperative complications in our study was $14 \%$ when compared to that of Mrunalsureshpatil et al., ${ }^{8}$ in which $8.8 \%$ cases had intraop complications.

Post-operative complications were seen in $24 \%$ of the cases when compared to Shimna Iqbal et al. ${ }^{9}$, in which $11 \%$ cases had post operative complications. PCR was seen in $2 \%$ of cases in our study (1MC and 1 NC), Mrunal Sureshpatil et al., found it in $2.4 \%$ of cases, Gogate et al. ${ }^{10}$ in $5.2 \%$ of the cases and Khanna RC et al., ${ }^{11}$ in $6.9 \%$ of the cases. Posterior capsule rupture most commonly occurred during irrigation aspiration \& due to extension of capsulorrhexis. As soon as the complication was noted, bridle sutures released, aspiration reduced \& anterior chamber was filled with viscoelastic material. In 10 cases which had vitreous loss, so open sky vitrectomy was performed \& PCIOL was implanted in ciliary sulcus in 5 cases. In the other cases IOL was placed in AC.

Premature entry was seen in 5\% (10 MC's, 10 IMSC, $5 \mathrm{NC}$ ) of the cases in our study, Mrunalsureshpatil et al., found it $1.2 \%$ of the cases, Yasir Iqbal et al., ${ }^{11}$ in $3 \%$ of the cases and Schroeder et al. ${ }^{12}$ in $1.5 \%$ of the cases.

Superior iridodialysis was seen in $1 \%$ of the cases in our study whereas Mrunalsureshpatil et al. noticed it in $0.4 \%$ of the cases and Gogate et al., in $0.5 \%$ of the cases and Zamanmir et al. ${ }^{13}$ in $1.6 \%$ of the cases.

In our study it was due to premature entry and inferior iridodialysis has also occurred in our study (1\%) which was during nucleus delivery with wire vectis. In both the cases it was small and no treatment was required. Improper construction of the scleral 
tunnel can lead to either button holing, if the tunnel is too shallow or premature entry, if the tunnel is too deep. The premature entry into the anterior chamber makes the tunnel less self-sealing therefore in such cases suturing was done using 10-0 nylon suture to close the wound at the end of surgery.

Iris prolapse was seen in 5\% of the cases in our study, Yasir Iqbal et al., found it in 3\% of the cases, Balmer et al., ${ }^{14}$ in $0.5 \%$ of the cases and Kongsap et al. ${ }^{15}$ in $7.3 \%$ of the cases. Iris prolapse was seen in (5\%) our study. Iris prolapse occurred during the delivery of nucleus in 1 case and in the other cases it was due to premature entry. In both the cases sutures were applied at the end of the procedure.

Zonular dialysis was seen in 3\% (2MC, $1 \mathrm{NC})$ of the cases in our study. Mrunalsureshpatil et al., noticed it in $0.8 \%$ of the cases and Khanna RC et al., in 3.8\% of the cases. In our study it occured most commonly due to weak zonules and small capsulotomy and in 5 cases it was due to a hard nuclear cataract.

DM tear was seen in $2 \%$ of the cases in our study. Mrunalsureshpatil et al., found it in $1.2 \%$ of the cases, Khanna RC et al., in $1.3 \%$ of the cases and Schroeder et al., in $0.7 \%$ of the cases. In our study it occurred probably due to faulty instrumentation. In all of these cases, air bubble was injected into the $\mathrm{AC}$ and sutures were applied.

Striate keratopathy in our study was seen in $20 \%$ of the cases where as Ratnakumar et al., ${ }^{16}$ found it in $21 \%$ of the cases.

Corneal edema in our study was seen in $17 \%$ of the cases where as Ratnakumar et al., found it in $19.5 \%$ of the cases. The commonest complication detected in early post-operative period was involvement of the cornea. This can be due operative technique or due to transient rise of intraocular pressure due to presence of the visco elastics substance. These patients were given hourly steroids, $0.5 \%$ timolol maleate drops and acetazolamide $250 \mathrm{mg}$ B.i.d for 2 days. Some of them required 5\% $\mathrm{NaCl} 5$ times a day. In all these cases, cornea got cleared in 3 days. Though it was a common complication, it didn't interfere with the final visual outcome.

Postoperative iritis was seen in $9 \%$ of the cases in our study whereas Ratnakumar et al., has noticed it in $3.5 \%$ of the cases. It most commonly occurred due to iatrogenic trauma to iris. It was brought under control with the help of systemic steroids and local steroids, NSAID eye drops and Cycloplegics.

Retained cortical matter was seen in $2 \%$ of the cases in our study where as Ratnakumar et al., has noticed it in $0.8 \%$ of the cases. In 5 cases it was small and fluffy and it was left behind, it got absorbed in a week and in the other case it was washed away on the 2nd POD.

The surgeon has to be extra careful with these structures, as postoperative inflammation and corneal edema can be all too common. More attention needs to be paid to cortical wash and capsular polishing, as PCO may be the only factor for suboptimal visual acuity in the future.

In our study, visual outcome of $6 / 18$ or better was seen in $89 \%$ of cases, where as in Ravindra et al., ${ }^{17}$ it was seen in $80.7 \%$ of the cases, Venkatesh et al., ${ }^{18}$ in $94.4 \%$, Kapoor at al., ${ }^{19}$ in $79.9 \%$ and Shimna Iqbal et al., in $93.3 \%$ of the cases.

\section{Conclusion}

MSICS has become an accepted and established procedure with more number of people accepting for this surgery. It is being performed in more than $85 \%$ of people undergoing surgery for cataract in our hospital.

The commonest cause of cataract is senile cataract and the most common type is senile immature cortical cataract $(44 \%)$ followed by Nuclear cataract $(41 \%)$.

There is less significant difference between sex $(\mathrm{M}: \mathrm{F}=46: 54)$.

Most of the cataracts were seen in 6th decade and above.

The commonest intraoperative complications were premature entry with Iris prolapse $(5 \%$ followed by zonular dialysis (3\%).

The commonest early post op complications were SK (20\%) and Corneal edema (17\%) but they responded well with steroids.

The commonest late post op complications were PCO (18\%) but it was satisfactorily treated with NdYAG Capsulotomy.

A significant astigmatism of greater than $1.5 \mathrm{D}$ was seen in $9 \%$ of the cases, but the visual outcome with glasses was satisfactory.

Post-operative visual outcome was $6 / 18$ or greater in $89 \%$ of cases.

\section{Summary}

1. MSICS is a safe surgery. The surgeon has to be extra deligent in tunnel construction as the tunnel size is larger. An excellent self-sealing incision is vital for wound architecture on which the safety and lowered astigmatism potential rests.

2. The incidence of posterior capsular rent and zonular dialysis is low, and in case of vitreous disturbance, it should be managed carefully.

3. In MSICS, the prolapse of nucleus into the anterior chamber and its delivery through the tunnel involve manipulations very close to the iris and cornea.

4. SICS gives best corrected postoperative visual acuity of $6 / 6$ or $6 / 9$ in a greater proportion of patients.

5. This technique has all the inherent advantages of the sutureless cataract surgery in terms of universal applicability, greater wound stability, lesser complications and early visual rehabilitation. This surgery is useful in high volume cataract surgery at lower cost which is the need of the hour in the developing world. 


\section{References}

1. Thylefors B, Negrel AD, Pararajasegram R, Dadzie KY. Global data on blindness. Bull World Health Organ. 1995;73:115-219.

2. Minasian DC, Mehera V. 3.8 million blinded by cataract each year: Projections of the first epidemiological study of incidence of cataract blindness in India. $\mathrm{Br} \mathrm{J}$ Ophthalmol. 1990;74:341-343.

3. Jose R. National programme for the control of blindness. Indian J Comm Health. 1997;3:5-9.

4. Yanoff M Duker JS. Lens surgery: Small incision cataract surgery. 1999;23:1-9.

5. Ernst PH Introduction to suturless surgery. In Gills JP, Sanders DR (Eds): small incision cataract surgery: foldable lenses, One stitch surgery, suturless surgery, Astigmatism, keratotomy. Thorofare NJ: Slack Inc.,1990, pp103-105.

6. Gogate PM, Wormald RP, Deshpande M, Deshpande R, Kulkarni SR. Extracapsular cataract surgery compared with manual small incision cataract surgery in community eye care setting in Western India: A randomized controlled trial. Br J Ophthalmol. 2003;87:673-679.

7. Gogate PM, Wormald RP, Deshpande M. Is manual small incision cataract surgery affordable in the developing countries? A cost comparison with extracapsular cataract extraction. Br J Ophthalmol. 2003;87:841-844.

8. Minasian DC, Mehera V. 3.8 Milion blinded by cataract each year: Projections of the first epidemiological study of incidence of cataract blindness in India. $\mathrm{Br} J$ Ophthalmol.1990;74:341-343.

9. Thulasiraj RD, Nirmalan PK, Ramakrishnan R, Krishandas R, Manimekalai TK, Baburajan NP, et al. Blindness and Vision Impairment in a Rural South Indian Population: The Aravind Comprehensive Eye Survey. Ophthalmology. 2003;110:1491-1498.

10. Gogate PM, Deshpande M, Wormald RP, Deshpande R, Kulkarni SR. Extracapsular cataract surgery compared with manual small incision cataract surgery in community eye care setting in western India: a randomised controlled trial. Br J Ophthalmol. 2003;87:667-672.
11. Khanna RC, Kaza S, Palamaner S, Shantha G.

Comparative outcomes of manual small incision cataract surgery and phacoemulsification performed by ophthalmology trainees in a tertiary eye care hospital in India: a retrospective cohort design. $B M J$. 2012;2:e001035.doi:10.1136/bmjopen-2012- 001035.

12. Iqbal Y, Zia S, Baig Mirza AU. Intraoperative and early postoperative complications of manual sutureless cataract extraction. J Coll Physicians Surg Pak. 2014 Apr; 24(4):252-5. doi: 04.2014/JCPSP.252255.

13. Schroeder B. Sutureless cataract extraction: complications and management; learning curves. Comm Eye Health J. 2003;16(48):58-60.

14. Balmer A, Andenmatten R, Hiroz CA. Complications of cataract surgery: Retrospectivestudy of 1304 cases. KlinMonstbl-Augenheilkd. 1991;198(5):344-346.

15. Kongsap P. Manual sutureless cataract surgery with foldable intraocular lens using the Kongsap technique: the results of 95 cases. J Med Assoc Thai. 2007;90 (8):1627-1632.

16. Indian Journal of Medical Case Reports ISSN: 23193832(Online). An Open Access, Online International Journal Available at http://www.cibtech.org/jcr.htm 2014 Vol.3 (1) January-March, pp. 37-39/ Rathnakumar and Baba.

17. Ravindra MS, Rekha G. Rural eye camp versus base hospital camp. Indian Ophthalmol.1996;44:303-4.2.

18. Venkatesh R, Muralikrishnan R, Balent LC, Karthik Prakash S, Venkatesh Prajna N. Outcomes of high volume cataract surgeries in a developing country. $\mathrm{Br} \mathrm{J}$ Ophthalmol. 2005;89:1079-1083.

19. Kapoor H, Chatterjee A, Daniel R, Foster A. Evaluation of visual outcome of cataract surgery in an Indian eye camp. Br J Ophthalmol. 1999;83:343-346.

How to cite this article: Chowdary N. L, Pradhan B. An overview of complications of MSICS. Indian $\mathrm{J}$ Clin Exp Ophthalmol. 2018;4(4):521-525. 